\title{
Discourses of Consumer's Alcohol Resistant Identities
}

\section{Shortened title: Alcohol Resistant Identities}

\author{
Marie-Louise Fry \\ Griffith University \\ Social Marketing @ Griffith \\ Griffith Business School \\ 170 Kessels Road, Nathan \\ Queensland, Australia 4111 \\ Email: m.fry@griffith.edu.au \\ Phone: + 61737357659 \\ Fax: + 61737357126
}

Submitted to:

Journal of Nonprofit \& Public Sector Marketing

Social Marketing Innovation - Special Issue (2011, Vol 23, No.4, pp348-366) 


\title{
Discourses of Consumer’s Alcohol Resistant Identities
}

\begin{abstract}
:
This study examines how abstinence from excessive drinking is meaningful to young people. By rejecting the dominant norm of intoxication young people engage in anti-consumption practices that involve degrees of anti-choice (Hogg et al., 2008). In this context, resistance is viewed as a source of innovation where consumers produce and co-produce a value paradigm that is oppositional to the 'dominant norm' of excessive drinking. Conceptualising alcohol consumption as a performance inclusive of different degrees of anti-choice contributes to a more nuanced view of how rejection operates alongside excess. Importantly, viewing alcohol consumption through a resistance lens reconsiders exploration of youth binge drinking beyond a dominant health paradigm of 'at-risk' behaviour with an understanding of value and the co-creation of value by consumers within a broader consumption environment.
\end{abstract}

Key words: alcohol, identity, non-consumption, young adults 


\section{Introduction:}

Most of my friends don't drink. I don't need to get drunk to have a good time. I'll have a drink every now and then ... it's just not an important part of my life. But it is for many other people and that's the problem. Alcohol is like the glue that binds people together, of how people interact with each other, how they socialise, how they meet. Getting drunk - no getting plastered - is what people do! (Francis, 23 years)

This excerpt illustrates the ubiquitous nature of alcohol in contemporary society and the importance of alcohol, as both an object and as a consumption practice, in building social relationships and identity. Yet not all young people drink to excess (National Health Prevention Taskforce, 2007; Fry, 2010, Piacentini and Banister, 2009; Coghill, Orme and Swindells, 2009). By resisting the prevailing culture of intoxication, are young people engaging in emancipatory practices to distance themselves from marketplace intoxication? Is resistance from intoxication simply a form of self-expression conveying a desire for social distinction? Or does non-consumption of alcohol represent a market bound perspective where lived experiences of resistance are a critical stance to consumption? To explore meanings young people attribute to not 'getting plastered' requires a broader conceptualisation of alcohol consumption beyond a focus on at-risk communities within a health paradigm targeting harm minimisation as its primary directive (Roche et al., 2008). The edict of developing 'safe, sensible' drinking cultures as a combatant to excessive drinking in UK and Australian alcohol policy enables actioning of an expanded view of alcohol consumption inclusive of rejection (e.g.: aversion, avoidance and abandonment) (National Alcohol Strategy, 2006; UK Department of Health, 2007). Considering the practice of consuming alcohol as a performance inclusive of rejection is to view the social issue of youth intoxication through a fresh lens, rather than only through a public health at-risk 
epidemiological perspective of problematic consumption. Nonetheless, research examining individuals' motivations for resisting prevailing norms of intoxication is largely rendered invisible (for exceptions see Nairn, Higgins, Thompson, Anderson and Fu, 2006; Piacentini and Banister, 2009; Valentine, Holloway and Jayne, 2010; Fry, 2010).

The purpose of this study is to explore the discourses of young adults who dialogically and diametrically resist intoxication, thus practice a form of anti-consumption in opposition to the dominant norm of intoxication. This study contributes to the alcohol research and social marketing literature by broadening the parameters within which alcohol consumption is viewed, that is, from a resistance lens. From this platform, the following section contextualises anti-consumption and resistance literature, and then considers the relationship between social marketing and consumer resistance to intoxication. The adopted methodology and study findings are then presented. The paper concludes highlighting the importance of viewing alcohol consumption as a performance inclusive of the spectrum of all possible consumption behaviour, including rejection through to consumption. With alcohol policy articulating creation of a culture where drinking to excess is socially unacceptable taking a more global view of the practices of alcohol consumption requires a shift alcohol rhetoric towards a model that has implications for the development of alternative sustainable prevention strategies.

\section{Anti-consumption and consumer resistance}

Anti-consumption as a domain of research has gained momentum over the past two decades. Simply, anti-consumption refers to the study of those who resist, defy or otherwise 'go against consumption' (Kozinets, Handleman and Lee, 2010; Holt, 2002). Predominantly, focusing on anti-activist movements to anti-brand discourses (Kozinets and Handelman; 
2004), from anti-globalisation demonstrations to utopian communities (Dobscha, 1998;

Bekin, Carrigan and Szmigin, 2005), from culture jamming to voluntary simplicity (Cherrier; 2009), from brand and category avoidance (Craig-Lees, 2006; Lee, Motion and Conroy, 2009), anti-consumption as a phenomenon reflects on resistance and the assimilation of resistance by the consumption culture requiring emancipation from the marketplace and the entire consumption process (Fontenelle, 2010). The interlinking theme across these forms of anti-consumption is the ability of individuals to 'withstand the force or effect of' consumer culture the marketing of mass produced things and meanings (Penaloza and Price 1993, p.123) or as a resistance to, distaste of, resentment or rejection of the consumerist ideal (Stammerjohan and Webster, 2002; Zavestoski, 2002). At a macro-level, anti-consumption represents the forces of the marketplace, the domination of corporations, the influence of marketing activities and/or brands within the marketplace (Fournier, 1998) against which consumers react. As anti-consumption inherently embraces acts of resistance (Lee, 2006; Hogg et al 2009) micro-level resistance represents individuals' capability to defy the domination of corporations operating within the marketplace, and is typically conceptualised through an individuals' desire for marketplace emancipation (Richardson and Turley, 2006; Penaloza and Price, 1993).

Recent advances in anti-consumption/resistance research illustrate movement towards investigating 'what consumers are doing with their behaviour'. Cherrier (2009) explores the importance of anti-consumption practices in the construction of consumer identity. Black and Cherrier (2010) challenge the underlying principles of consuming anti-consumption for sustainability, with Eckhardt, Belk and Devinney (2010) exploring consumer's justifications for not consuming ethically. Investigating how consumers create new consumption communities to achieve a better balance between production and consumption processes 
Bekin, Carrigan and Szmigin (2005) recognise the interplay between ideology of anticonsumption and individuals redefining their position in the marketplace to regain control from market domination. This new era of anti-consumption research distinguishes the challenges and conflicts faced by anti-consumerists when enacting their resistant behaviour. The ideology of anti-consumption to some degree conflicts with the daily practice of anticonsumption for sustainability (Black 2010) requiring consumers to negotiate and consolidate how they redefine the production-consumption process (Bekin, Carrigan and Szmigin, 2005). Rather than complete rejection, anti-consumption practices of rejection balance ideological positioning with practicality.

Thus, while resistance is a natural outcome of the dynamic relationship between social institutions (firms and branding paradigms) and consumer culture, consumers respond by engaging in market-sanctioned cultural experimentation through which the market rejuvenates itself (Izberk-Bilgin, 2010; Holt, 2002). In this way, recent conceptualisation of resistance is considered as a lived experience concerned with personally enriching and liberating aspects of its practice, rather than as a critical stance against consumption (IzberkBilgin, 2010). Like consumption, practices of resistance as a subset of anti-consumption may be both material and discursive, entail objectives and a 'way of doing things', and integrate a self-imposed regulation through sustained reflection. As Lee (in Kozinets, Handelman and Lee, 2010, p.225) clarifies: 'anti-consumption does not preclude consumption, that the two phenomena must surely co-exist and that the reasons people have for going against consumption are just as interesting as the reasons they have for consumption'. Not only is there an interplay between consumption and anti-consumption, but also that the practice of sustainable anti-consumption represents a shift in consumers' decision-making with resistance entailing a purposive behaviour. In this way, resistance as an alternate consumption 
behaviour operates in opposition and alongside culturally established or ritualised marketplace behaviours.

\section{Social marketing and consumer resistance to intoxication}

The notion of rejection and/or reduced consumption as a choice within all possible consumption behaviours available to individuals sits at the heart of social marketing. Inherently, social marketers are seeking to develop durable (sustainable) social change requiring the target group to maintain an advocated altered behaviour over the longer term (Andreasen, 1995). Yet, as Brennan and Binney (2008) point out enacting social change from institutional and individual perspectives yields a social marketing/sustainability dilemma. Focussing on the institutional perspective, the dilemma centres on the hegemonic role of health governing the harm minimisation approach of prevention strategies, particularly in alcohol and drug contexts. Despite health discourse and research as replete in explaining consumer's motivations for excessive consumption (e.g. youth intoxication), this perspective considers only 'one side of the coin'. Rather than intoxication acting as the only conduit for the production of credible identity positions, there exists a subset of young people who have no desire to be recognised by the dominant norm, actively resist the dominant norm and/or opt out of belonging to the prevailing culture of youth intoxication (Fry, 2010; Paicentini and Banister, 2009). Yet, can performing or not performing an action, in this instance intoxication, be viewed simply as oppositional?

While performing an action (e.g. consuming alcohol) and not performing the identical action (e.g. not consuming alcohol) can be considered as logically opposite, sometimes the negated action can implicitly point to an indefinite number of alternate actions (Kruglanski, Shah, Fishbach, Friedman, Chun and Sleeth-Keppler, 2002). As Richetin, Connor and Perugini 
(2011) establish the reasons (i.e.: goals) for performing or not performing a behaviour (doing physical exercise, eating meat, and breastfeeding) can be better characterised as relatively separate rather than opposite processes suggesting that the pathway to action or inaction can be different, but not necessarily mutually exclusive. With reference to alcohol consumption, the consideration of consumption as not diagrammatically oppositional in terms of drinking or not drinking opens a space for researchers to consider alternative continuums or overlapping behaviours. Recent articulations of contemporary alcohol policy inclusive of creating a 'safer, healthier drinking culture' has important implications for broadening the lens through which youth intoxication is viewed (National Alcohol Strategy, 2006; UK Department of Health, 2007). Not only does the new policy rhetoric offer a sustainable approach to excessive alcohol consumption, but also represents a repositioning of alcohol discourse towards a paradigm of cultural inclusiveness signified by a subtext of positive socialisation, as opposed to culturally exclusive signified by a subtext of individual harm and social violence (Fry, 2010). By actively seeking to de-normalise youth intoxication through 'safer, healthier drinking cultures' alcohol consumption can be considered along a behavioural continua inclusive of discrete, yet overlapping, typologies of performance practices ranging from rejection of alcohol/intoxication, to sensible/responsible/moderate drinking, and extreme alcohol consumption (intoxication, binge drinking).

Drawing on the parallels of anti-consumption/resistance literature and extending the notion of alcohol consumption as a performance involving a variety of behaviours enables contextualisation of market resistance to intoxication. To date, the majority of sustainable social marketing is discussed around issues concerning the environment (McKenzie-Mohr, 2000) with little reference beyond issues concerning de-marketing littering behaviour, promoting recycling behaviour, promoting eco-literacy or energy efficiency. As a discipline, 
health-related social marketing is entering a new level of consciousness. Extending beyond the narrowly governed epidemiological 'at-risk' view of health issues social marketers are moving towards understanding that consumption is dynamic and socially constructed. What is new is the recognition that alcohol consumption is engendered via a wider, and interrelated, set of social forces and conditions (Measham and Brain, 2005) with researchers attempting to make sense of the person as an actor in the social space, as a social subject (Cherrington, Chamberlain and Grixti, 2006; Szmigin, Bengry-Howell, Griffin, Hackley and Mistral, 2010). Individuals actively transform symbolic meanings from consumer culture to further their identity position and lifestyle goals, which is continually fashioned and co-produced with other partners within the social space (Shanker, Elliot and Fitchett, 2009). This reciprocal relationship between identity and culture is integral as interaction of social practice authenticates an individual's identity, with the self implicitly embedded in social practice. Considering the interplay between resisting states of intoxication and consumer culture this study sheds light on consumer resistance within an alcohol context. Specifically, the objectives of this study are twofold: 1) to uncover the resistance and alternative consumption attitudes and behaviours to intoxication, and 2) to advance alcohol-related social marketing by broadening the parameters within which alcohol consumption is viewed.

\section{Methodology:}

The qualitative study was conducted with twenty young adults aged 18-25 years who identified themselves primarily as 'non-drinkers' or 'responsible drinkers' preferring to drink one or two drinks when socialising. A subset of informants $(n=8)$ who actively embrace alcohol were included in the study for purposes of exploring 'time out from alcohol'. Interviews were conducted in metropolitan areas on the east coast of Australia (Brisbane, Gold Coast, Newcastle, Sydney and Melbourne). These locations were chosen to gain 
broader understanding of the complexities of integrating within or beyond urban areas dominated by intoxicated leisure spaces. Discussions followed Thompson, Locander and Pollio's (1989) long interview design which proceeds in a conversational manner concerning informant's relationship with alcohol and their integration/socialisation within and/or beyond the night-time economy. Participants were encouraged to recall salient moments in their relational lives, organise these thoughts, and make sense of these experiences through story telling or an organised telling of experiences (Thompson and Haytko, 1997; Fisher, 1987). This interpretative approach encourages exploration of participant's "lived experiences" where the use of everyday language becomes imperative for gaining common sense and practical understanding of participant's real life stories.

Interview guides provided a general framework for discussion and were frequently revised to reflect identification of new issues, gain deeper meaning of descriptions of new information and exploration of unanswered questions. Focus groups were led by age-relevant researchers in the aim creating a more conducive environment for participants to discuss their drinking behaviour. Interviewees were given extensive instruction and training in interpretive research methods, had previous experience in collecting qualitative data, and were closely supervised by the senior researcher.

The method of analysis of participant's lived experiences used a hermeneutic approach (Thompson and Hirschman (1995) applying a modified constant comparative method iteratively noting similarities and differences across individual transcripts (Wooten, 2000; Thompson, 1997). Hermeneutic reasoning presumes "understanding develops as earlier readings of a text serve to inform later ones and, reciprocally, later readings recognize and explore patterns that had not been previously noted" (Thompson and Hirschman, 1995: 141). 
Consequently, interpretation of data emerged from an interplay between initial theoretical insights and enquiry of participants actual lived experiences through the conduct of the study. The interviewees and senior researcher independently read through the entire set of transcripts to agree the overall shape, meaning and context of reported experiences. Individual lines of transcript were sorted and constantly compared to generate thematic categories that served to explain individual experiences of creating credible responsible drinking identities within a culture of intoxication.

\section{Analysis and discussion:}

The analysis presented considers participants interpretations of socialising without alcohol or with limited alcohol in leisure environments where intoxication is the dominant norm. The findings show that individuals clearly practice levels of resistant alcohol consumption practices shaped by their self-concepts. Informants offered a myriad of sustainable practices using discourses of health, self worth, and respect. Motivations for health-related commodities of responsible consumption of alcohol, including non-consumption, are guided not so much by health investments but rather in terms of self-expressions. Theme one explains how the aesthetics of resistance is cultivated from the interplay between the consumer and consumer culture. Theme two explores individuals' purposive behaviour of anti-choice to re-create marketplace traditions when a consumer does not engage in culturally established or ritualised marketplace behaviour. Theme three contextualises alcohol resistance through the lens of personal gratification.

\section{Aesthetics of resistance:}

All informants are clearly aware consumption does not occur within a vacuum; that culture plays an integral part of any consumption practice. In this study, informants evaluate their 
integration within or beyond intoxication spaces as non-participants in the intoxication culture and describe themselves as having an alternative subject position that is in opposition to the prevailing drinking culture. All narratives depict a clear relationship between identities and resistant behaviours. Informants explained their choices to adopt alcohol-related anticonsumption practices as part of their pursuit of desired identities, with resistance acting as the expression of their credible identity. Informants evaluate their decision to act against the prevailing culture of intoxication as a consequence of the abject symbolism of the intoxicated person. Although references to health choices or health consequences of excessive intoxication were acknowledged, informants' narratives depict a clear relationship between subject position and self-expression. As expressed in the excerpt below, health consequences are not necessarily key motivators for practising alcohol anti-consumption.

Vicki: I don't not drink because I think it's good for me. I like to look good. I take pride in my appearance. I don't actively think about the health consequences of why I prefer not to get drunk - longer life, not having a hangover, damaged brain cells or liver. I see others putting on weight from drinking too much too frequently... and the bad skin, breakouts and not to mention the bad breath.

Throughout her narrative Vicki expresses caring about her appearance as a key value, while acknowledging health related benefits exist they were not fundamental for engaging in resistant alcohol behaviour. Similarly, Susan expresses her resistant identity through her 'strong outrageous personality' that 'hides the fact that she is not drinking' and Peter acknowledges that 'a beer belly is not conducive to hitting on chicks'. There was some discussion concerning the impact of drinking and meeting new people 'with first appearances being a huge factor in meeting that special person'. For Alison, health motivations for her 
resistant alcohol identity are not constrained to a medically defined state of being but rather through symbolic experiences of integrating within the intoxicated environment, but not. Alison: I like to think that people accept me when I'm out with others who drink. My close friends accept that I don't drink but it's so much easier to have a good time without explaining that I don't drink. So I pretend I'm drinking with a champagne glass filled with soft drink that looks like it has bubbles. Does the trick.

For Mike, the symbolic expression of his alcohol resistant identity is provided through status elevation through the eyes of other drinkers. As an ex-drinker Mike is able to engage with drinkers through war stories and 'heroic' notions of 'knowing what is was like to be drunk, drink to intoxication and survive the night'. Significantly, Mike's capability to participate provides him with instant credibility and acceptance of his alcohol resistant identity. As Mike reflects 'people don't bother me about it, they know I don't drink and I like that I'm considered cool and not a nerd... well people know I did some crazy things which they wouldn't do .. so I suppose I'm considered a dare devil .. as a risk taker. When I think about it that's just crazy but I'm left alone.'

The analysis in theme one suggests the subject positions of alcohol resistant consumers does not rely on medically defined constructions of health. Across the sample, informants' core identity as alcohol resistant consumers prioritises the pursuit of desired self through aesthetics of self-expression. This finding contributes to the knowledge gathered from consumer culture theorists recognising behaviour does not occur in a vacuum, but rather from the interplay between consumers acting within the social space. 


\section{Degrees of anti-choice: aversion and avoidance, integration, abandonment}

When considering the practice of resistance behaviour Fournier (1998) considers anticonsumption resistant identity along a continuum ranging from avoidance behaviours to minimisation behaviours to active rebellion. Each informant discussed how they practiced resistance to intoxication within their daily lives. It is clear intoxication was resisted across all informants; however the practice of anti-consumption was interpreted and enacted differentially. Kate expresses her emancipation from intoxicated leisure spaces through aversion and avoidance explaining:

Kate: I just don't like the taste of alcohol and can think of more productive things to do than 'to get drunk'. I don't have anything against people drinking but it's when they get totally wrecked. I just don't get why it's the rage to get drunk, behave badly and they think it's cool. What's so cool about spewing up all over the place?

For Kate, the notion of intoxication as abject and a futile practice is a strongly held belief influencing her identity as a non-drinker. Kate acknowledges that 'it is easy not to go to bars, pubs and clubs as all her friends' are also non-drinkers. Morally, Kate is concerned that it is possible that a 'number of young people will end up being alcoholics', considers young people who drink just to get drunk as 'just stupid' and views life as full of unexplored potential: 'as Forest Gump says 'life is like a box of chocolates' and there is so much to do ... I certainly don't want to waste my time doing stupid things'. Similarly, Vicki and Alison view intoxication as 'morally abusive to the body'. Alison morally avoids alcohol and intoxicated leisure spaces as alcohol is not acceptable within her Muslim religion. For Alison, religion provides a strong alternative belief constellation for avoidance, yet notes that she needs to 'balance her beliefs about alcohol with those that others have'. Alison 
acknowledges that her religion guides her 'way of life' and provides a community bounded by rules, beliefs and moral structure which 'easily enables avoidance'.

Although Kate, Alison and Vicki all express aversion to intoxication through their 'dislike to socialising with too many drunk people', Vicki realises that without socialising within intoxicated leisure spaces she 'foregoes meeting up with friends and having good time'. For Vicki to practice her identity as a non-drinker she carefully balances her identity with opportunities to meet with friends, party and have a good time. By manoeuvring within intoxicated spaces, yet without drinking, Vicki illustrates resistance through integration. This combination of resistance and integration challenges stereotypical, well established and often unspoken conventions of 'how one should act' within the alcohol-fuelled environments; requiring drinkers to redefine the construct of fun, enjoyment and socialisation (Fry, 2010). As Mike, who stopped drinking because 'it got too much', illustrates 'it's interesting when people realise that you don't drink they're a bit weird at first but cause you're having a good time they just accept it'. Vicki comments 'buying drinks for a non-drinker is a bit of a challenge for drinkers... but I think people are more accepting now that some people just don't drink'. She further comments: 'I generally try to hide that I'm a non-drinker. When I buy my drinks I ask the barperson for a wine glass to put my soda water or lemonade in. This way I don't look different, people think I'm drinking a fizzy wine!'. Throughout her narrative Vicki is cognisant of belonging and acceptance among peers within her social set.

Alternatively, Bob often states that he 'takes the role of the driver for the night' not wanting to miss out on 'the fun'. In this instance Bob takes on a functional role driven by his innate desire 'to make sure my friends get home at night safely'. While at times finding this role frustrating 'cause I often have to wait around at night', Bob identifies that he would 'prefer 
to hang around than wake up one morning finding out a friend had driven home drunk and died'. The assumption of roles provides authenticity and legitimacy to Bob's identity as a non-drinker, while simultaneously requiring management of affiliation goals (wanting to be a good friend) and role responsibility (anxious not to hang out to all hours of the night), as similarly found by Piacentini and Banister (2009).

While some informants actively resist alcohol through practices of abandonment, a subset of informants' were included in the study to examine 'time out from alcohol'. Lucy and John enjoy consuming alcohol as 'it's the Australian way of life' symbolising enjoyment, relaxation and socialisation, yet are willing embrace 'time out from alcohol' by participating in the Australian initiative of febfast. Febfast asks individuals during the shortest month of the year to forgo alcohol, to work towards a healthier lifestyle, save money while supporting youth related alcohol and drug research, prevention and services (febfast website). Rejection of alcohol for a short period of time shows that resistance as a construct may take on a less then permanent status. For example Lucy expresses the challenges and outcomes of participating in limited abandonment.

Lucy: It's just after Christmas... it's summer in Australia... lots of time at the beach, socialising, generally enjoying life. January is the ritual for beach holidays, lots of excess and enjoying a glass or two of wine. Then it hits you. That drinking has become an essential part of enjoying life. So febfast is just great. It's the shortest month of the year which psychologically is very important. It's a lot of effort and at first you have to consciously think about doing other things rather than having a glass of wine. But after a little bit it's fun and you're being very productive with your time. From a personal achievement perspective February is not only a rewarding month but where I set up yearlong projects and goals for myself. I don't even mind other 
people drinking around me towards the end. It was nice to know I was in control of alcohol not the other way round!'

Similarly, Helen views febfast as a ritual, as 'something she does every year' to recapture a sense of perspective about personal behaviour and thinking around alcohol use. The sense of community is achieved through identification of creating a 'space for change' at both a personal and societal level. As Helen acknowledges 'there is now a community around febfast and I don't have to continually inform people of what it is all about. It was like I was a recording; all you had to do is press play. Now people are more interested in creating activities to diverge their habitual behaviour away from pouring a glass of wine'. For Ben, febfast is a way of 'getting fit with your mates' building camaraderie through sports rather than sitting around 'getting pissed'. Natalie expresses value from participating in febfast through new friendships forged, 'who not only provide a support system throughout febfast but also continued friendships beyond'.

In all limited abandonment narratives the concept community through rejection was an important aspect of creating a space to consider alcohol use in the short term, as well as longer term consideration of alcohol consumption in life. The community enabled a space to share a commonality, identity with other fasters, and a sense of purpose. Importantly, the community not only enabled capability 'to do' the rejection behaviour, but enabled 'the doing' without fear of being stigmatised for acting outside the mainstream. By putting a pause on alcohol, particularly after a period of excess, limited abandonment informants achieved a heightened awareness of how alcohol can affect the body, and importantly selfefficacy in creating personal change. On the one hand, commencing the process of rejection requires drastic changes in daily life activities. On the other hand through the process of 
detachment resistance fuels future possibilities with the creation of replacement activities enabling a shift of identities and future selves. As Helen expresses 'the best part about febfast is losing a few kilos, however I'm really going to have to make some changes now that I'll be having those glasses of wine so I don't put them back on'.

Theme two illustrates informants' practice of alcohol resistance within the broader market space dominated by intoxication. Informants reflected on their personal level of anti-choice through aversion and avoidance, integration and abandonment suggesting that not all alcohol resistant behaviour is the same. Drawing on Fourniers' (1998) continua of anti-resistant consumption informants in this study engage in a diverse range of alcohol resistant practices that are not necessarily mutually exclusive. Informants define a space, which may or may not involve compromise, within which to practice their alcohol anti-consumption enabling the expression of their resistant identity to be fulfilled.

\section{Resistance as personal gratification}

Extending Izberk-Bilgin's (2010) conceptualisation of resistance as a personally enriching and liberating lived experience this section explores how the practice of resisting alcohol is aligned with long held core values and beliefs. Many intoxication resisters view their resistance behaviour as an intrinsically satisfying activity. Rather than viewing intoxication resistance as an end in itself, informants themselves co-produce their identity within a larger social space alongside their 'other' consumer selves. From this perspective, informants constantly define and redefine who they are (identities) and who they want to be (desired identity) within a dynamic market space. Importantly, it is the value consumers co-create through interaction and relationships, in this instance resistance behaviour, that results in a desire for distinction within the market rather than ideological opposition to the market. To 
illustrate this, Kate explains how not drinking alcohol aligns with a deeper values of 'experiencing life' and 'not wasting money'.

Kate: I am always thinking about how I can best use the money I earn. I've always been this way. My mum has always said 'she 'll go a long way on a penny!'. I like to experience life - go to the theatre, travel, and do things that I think one day I might not be able to do once I have kids and settle down. It's not that I won't be able to do them but priorities will change. I'm not a dare devil or anything I just don't like to waste my money. I see alcohol as a waste of money. Having nice things and being able to do things is a priority. At the moment I'm saving up to buy a unit.

It is clear Kate's alcohol resistant identity does not preclude her from the marketplace; rather her practice of resistance enables her to engage within the market to further produce her identity. At first glance, Kate's narrative reveals objective evaluations for practicing alcohol resistance based on price. Yet through the act of resistance Kate is not only able to coproduce her alcohol resistance identity, but also enhance her other social and personal identities. Importantly, her anti-consumption practice enables Kate to improvise her own experiences, goals, interest and social circumstances. Kate is a 'saver', a 'traveller', a 'culturalist', and considers life as a 'journey to be lived and experienced'.

For Mike, alcohol anti-consumption gives him a sense of being able to engage and excel in sport activities facilitating belonging to a diversity of sporting communities.

Mike: Sport is what I love. I'm one of those lycra lovers riding my bicycle with friends on a Sunday. I run with an organised group three mornings a week, row in winter, and swim in summer. I'm always doing something - if I have a weekend off and the weather is good I'm off to the coast to surf. Nothing pumps the adrenalin than getting 
out there on a wave. That's my life. My social life is my sport and my sport is my social life.

In Mike's narrative embracing resistance allows him to fulfil his desired self. Resistance sits within a broader conceptualisation of the self, rather than at the forefront of identity. Mike acknowledges that he does not drink alcohol, is comfortable with this expression but 'does not think about it too much', and overwhelmingly considers his sporting self as an avenue for self-expression, personal fulfilment and social belonging. Inherently Mike's sporting identify fuels the personal respect he has for health and objectification of health. Similarly, Vicki, who likes to 'look good' explains her choice to adopt an alcohol resistant identity is based on expressions of beauty, health and 'respect for the body'. Her core values evolve around maintaining a 'healthy, positive life, yet without being too hung up on it', simultaneously recognising greater ambitions in life. For Vicki, the personal gratification of not drinking opens a space for her to align her individual self with her aspirations, goals and future self.

Vicki: I love waking up in the morning and going for a run. I eat healthily and mmm have chocolate and chips as treats. Part of it is about the adrenalin of doing exercise, part is about looking after yourself, but mostly it's about the heart, body and mind! Life is pretty tough out there and you just have to be prepared. Being switched to the positives - glass halffull rather than half empty - I'm able to see the bigger picture, know where I'm going and set goals to get there. I did pretty well at school and uni and am thinking of doing further study but am not sure.

Limited abandoners of alcohol who take time out from alcohol for limited periods of time view their resistance behaviour as a personal achievement 'for getting through it and finding that it was OK not to drink, even when socialising'. Some mentioned the act of discussing 
motivations for resisting alcohol through the febfast initiative further enhanced their own pride, respect for self and thinking about the bigger picture that 'you can do life without alcohol infiltrating all aspects of both social and individual' worlds. Limited abandoners found a new sense of self through the practice of anti-consumption enabling them to identify with a 'new person that didn't know existed'. To illustrate this Helen expresses in the excerpt below her insight into how alcohol resistance enables a more fulfilled self.

Helen: 'I've really found that I look forward to febfast. It's like I give myself time out to find myself and to give my life a new direction. I don't necessarily stop socialising, actually I probably do more with my friends, but it's like mmm not sure... like selfgranted permission to actively think about what direction my life is taking and to take some initiative about how to get there. I really like the process and like the person I am for taking the step to take stock rather than letting life pass you by.

This third theme shows that informant identities and desired identities occupy a space that allows diverse practices of resistance to be enacted, which in turn strengthens both existing and desired identities. Multiple discourses support the notion that informants actively interact with a vast array of social realities within contemporary culture to construct representations of the self and negotiate their collective identities in relation to social situations, roles and interactions (Arnould and Thompson, 2005). The practice of alcohol anti-consumption, even for limited abandoners, balances self-interested motivations alongside rejuvenation of the self, involves a diversity of values interwoven into the act of rejection, while simultaneously producing and co-creating value as determined by the individual into a heightened selfexpressive identity project 


\section{Conclusion and implications:}

As Lee argues (2009) consumption cannot adequately be understood without attention to its counterpart anti-consumption. Drawing on the literature of anti-consumption and consumer resistance, this paper endeavoured to understand anti-consumption within a social marketing context. Analysis focused on characteristics of anti-consumption of alcohol and meanings ascribed to the practice of sustainable rejection. In line with more recent conceptualisations of anti-consumption and resistance discourse, the practice of alcohol anti-consumption by informants in this study occurred across a diverse range of resistance possibilities suggesting that not all resistance behaviour is the same (Fournier 1998, Cherrier and Black, 2010, Hogg, Banister and Stephenson, 2010). This research identifies typologies of alcohol resistance situated around practices of 'avoidance', 'abandonment', 'aversion', and 'integration', yet the typologies are not within constricted, fixed boundaries. In the endeavour to express resistance identity informants morph across these typology borders with the permutation of expressions and strength of feelings towards expressions enabling representations of different degrees of anti-choice (Hogg, 1998). Thus, while the practice of resistance may be discretely classified, a more valid approach is to view these phenomena as a continuum of expressions extending from 'abandonment', to 'avoidance', to 'integration'.

Alcohol resistance through anti-choice can be understood as the assertion of oppositional stance to the tastes of others, rather than as a means to enact social change through emancipation from the market (Hogg and Savolainen, 1998; Penaloza and Price, 1993). In this instance, 'taste' is primarily a 'distaste' to the identity associated with another set of tastes, which, in turn, enables the construction of an alternate consumption behaviour that operates in opposition, within and alongside established and/or ritualised marketplace behaviours (Richardson and Turley, 2006). Drawing on parallels of Hogg, Banister and 
Stephenson's (2009) mapping of anti-consumption behaviour, alcohol resistance assumes multiple forms with varying degrees of visibility and exemplifies complexity in the interaction between expressions, tastes and distastes. Based on key attitudinal components expressions of 'abandonment', 'avoidance' and 'integration' are strongly connected to the behavioural acts of attitudes, with expressions of 'aversion' strongly linking to the affective aspects of attitudes (Hogg, Banister and Stephenson, 2009). Aversion, as expressed through dislike, disgust and revulsion towards alcohol stimulates behavioural responses of avoidance (staying away from intoxication leisure spaces), abandonment (giving up alcohol or giving up socialising in intoxicated leisure spaces) or integration (socialising within alcohol fuelled leisure spaces while maintaining resistance identity). Abandonment combined with avoidance represents one end of the continua with informants' determination to exclude themselves from alcohol fuelled environments. Aversion combined with integration illustrates alcohol anti-consumption does not require emancipation from the marketplace, but rather a desire for representation within the alcohol fuelled marketplace. Modification of resistance behaviour by integrators suggests informants are willing to forego their expressions of alcohol resistance identity as a means to facilitate acceptance within alcohol fuelled leisure spaces where identity is subsumed as 'not being different'.

Current perspectives of health-related social marketing is bounded within a narrowly defined health discourse neglecting the extent to which alcohol consumption is engendered by social, symbolic and cultural meanings. New policy edict addresses the consensus that challenging youth-related problematic drinking will require cultural change towards a mores where choosing not to drink excessively is socially accepted (Measham and Brain, 2005; Piacentini and Banister, 2009). Yet, to make this possible, policy makers, health professionals and social marketers need to provide greater guidance on how to develop a culture where not drinking is 
socially acceptable. This new policy edict implicitly requires consideration of how consumers reject consumption or manage sensible consumption of alcohol within intoxicated leisure spaces as part of all possible behavioural repertoires. Conceptualising alcohol consumption as a performance inclusive of different degrees of anti-choice contributes to a more nuanced view of how rejection operates alongside excessiveness and how consumers create and cocreate resistance value within a broader consumption environment. This allows alcohol resistance to be viewed as a sum of values where drawing on discursive fields bounded by other social realities (health, body image, travel) informants' future possible selves are fashioned and co-produced through integration within contemporary culture. Thus, from a policy perspective opening the sphere to consider alcohol anti-consumption through the lens of resistance and consumption reduction has positive implications for the framing of research to explore ideas of alternate prevention frameworks which has direct bearing on the questions and concerns of researchers working within the alcohol research environment.

A useful way forward from a social marketing perspective may be to explore ways of engaging the sociality of young people's drinking as a viable exchange offer, rather than current educational perspectives showing ramifications of drinking too much. Febfast provides a useful way to consider how resistance, albeit for a limited time, influences attitudes towards individual drinking behaviours. As a consumption community febfast enables sharing of anti-consumption through every day resistance practices and integration within alcohol-fuelled leisure spaces. By taking a more global view of the impact of alcohol febfast offers individuals a shared space where people are bound together by a common activity, commodity use and language. Febfast as a social movement is clearly defined, in both time and space, allowing individuals to become more self-confident and vocal about their alcohol resistance position. Similarly, integrators illustrate capability to morph within 
and beyond intoxicated leisure spaces adopting multiple strategies to subsume resistance identity without abandonment. These behaviours offer social marketers and health practitioners a useful starting point for identifying credible exchange alternatives facilitating responsible consumption of alcohol.

As Cherrington et al., (2006) argue recruiting youth towards an agenda of 'appropriate' consumption requires more than environmental controls on pricing or availability. It is evident that current prevention strategies (responsible service of alcohol, police strategies, price and availability strategies) alone are not sufficient to tackle youth intoxication. It is now time for policy makers, health practitioners and social marketers to shift the alcohol rhetoric towards a model that encompasses the full spectrum of alcohol consumption inclusive of not only consumption but also practices of rejection that is more representative of a sustainable approach to alcohol consumption. 


\section{References:}

Andreasen, A. R. (1995). Marketing social change: changing behavior to promote health, social development, and the environment. San Francisco: Jossey Bass.

Arnould, E.J., and Thompson, C.J. (2005). Consumer Culture Theory (CCT): Twenty years of research. Journal of Consumer Research, 31 (4), 868-882.

Bekin, C., Carrigan, M., and Szmigin, I. (2005). Defying marketing sovereignty: voluntary simplicity at new consumption communities. Qualitative Market Research: An International Journal, 8(4), 413-429.

Black, I.R. (2010). Sustainability through anti-consumption. Journal of Consumer Behaviour, 9, 403-411.

Black, I.R., and Cherrier, H. (2010). Anti-consumption as part of living a sustainable lifestyle: Daily practices, contextual motivations and subjective values. Journal of Consumer Behaviour, 9, 457-453.

Brennan, L., and Binney, W. (2008). Concepts in conflict: Social Marketing and sustainability. Journal of Nonprofit and Public Sector Marketing, Vol. 20(2), 261-281.

Cherrier, H. (2009). Anti-consumption discourses and consumer-resistant identities. Journal of Business Research, 62(2), 181-190.

Cherrington, J., Chamberlain, K., and Grixti, J. (2006). Relocating alcohol advertising research: Examining socially mediated relationships with alcohol. Journal of Health Psychology, 11(2), 209-222.

Coghill, N., Orme, J. and Swindells, M. (2009). Sensible drinking amongst students in Higher Education Institutions in the South West Region: A 'Snap Shot' of current Practice. School of Health and Social Care University of the West of England, Bristol

Craig-Lees, M. (2006). Anti-consumption: concept clarification and changing consumption behaviour. Paper presented at the anti-consumption seminar, International Centre for AntiConsumption Research, June 20-21, Auckland, New Zealand.

Dobscha, S. (1998). The lived experience of consumer rebellion against marketing. Advances in Consumer Research, 25(1), 91-97.

Eckhardt, G.M., Belk, R., and Devinney, T.M. (2010). Why don't consumers consume ethically?, Journal of Consumer Behavior, 9(6), 426-436.

Febfast website: http://febfast.org.au/ (accessed 20 July 2011).

Fisher, W. (1987). Human communication as narration: Toward a philosophy of reason, value, and action. Columbia: University of South Carolina Press. 
Fontenell, I.A. (2010). Global responsibility through consumption? Resistance and assimilation in the anti-brand movement. Critical Perspectives on International Business, 6(4), 256-272

Fournier, S. (1998) Consumer resistance: societal motivations, consumer manifestations, and implications. Advances in Consumer Research, 25 (1), 88-90.

Fry, M.L. (2010) Countering consumption in a culture of intoxication. Journal of Marketing Management, 26(13), 1270-1294.

Hogg, M. (1998). Anti-constellations: exploring the impact of negation on consumption. Journal of Marketing Management, 14, 133-158.

Hogg, M., Banister, E. N., and Stephenson, C.A. (2009). Mapping symbolic (anti-) consumption. Journal of Business Research, 62(2), 148-159.

Hogg, M., and Savolainen, M. (1998). The role of aversion in product/brand choice. In Alba, J.W. and Hutchinson, J.W. (Eds), Advances in Consumer Research (Vol. 25, p.89), Valdosta, GA: Association for Consumer Research.

Holt, D.B. (2002). Why do brands cause trouble? A dialectical theory of consumer culture and branding. Journal of Consumer Culture, 29, 70-90.

Izberk-Bilgin, E. (2010). An interdisciplinary review of resistance to consumption, some marketing interpretations, and future research suggestions. Consumption, Markets and Culture, 13(3), 299-323.

Kozinets, R.V., and Handelman, J.M. (2004). Adversaries of consumption: consumer movements, activism and ideology. Journal of Consumer Research, 31 (3), 691-704.

Kozinets, R.V., Handelman, J.M., and Lee, M.S.W. (2010). Don't read this; or, who cares what the hell anti-consumption is. Consumption, Markets and Culture, 13(3), 225-233.

Kruglanski, A. W., Shah, J. Y., Fishbach, A., Friedman, R., Chun, W. Y., and SleethKeppler, D. (2002). A theory of goal systems. In M. P. Zanna (Ed.), Advances in Experimental Social Psychology (Vol 34, pp. 331-378), San Diego, CA: Academic Press.

Lee, M. (2006). Anti-consumption research: Exploring the boundaries of consumption. In G.G. Davis and Craig-Lees, M. (eds), Asia-Pacific Advances in Consumer Research (73-74), Duluth, MN: Association for Consumer Research.

Lee, M., Motion, J., and Conroy, D. (2009). Anti-consumption and brand avoidance, Journal of Business Research, 62, 169-180.

McKenzie-Mohr, D. (2000). New ways to promote proenvironmental behavior: Promoting sustainable behavior: An introduction to community-based social marketing. Journal of Social Issues, 56(3), 543-554.

Measham, F., and Brain, K. (2005). Binge drinking, British alcohol policy and the new culture of intoxication. Crime Media Culture, 1(3), 262-283. 
Nairn, K., Higgins, J., Thompson, B., Anderson, M., and Fu. N. (2006). It's just like the teenage stereotype, you go out and drink and stuff: Hearing from young people who don't drink. Journal of Youth Studies, 9(3), 287-304.

National Alcohol Strategy (2006; extended to 2011). Towards safer drinking cultures. Publication No: 3900. Commonwealth of Australia.

National Preventative Health Taskforce (2009). Australia: The Healthiest Country by 2020. Preventative Health Strategy - The Roadmap for Action. Publication No: P3-5444.

Commonwealth of Australia.

Penaloza, L. and Price, L.L. (1993). Consumer resistance: a conceptual overview. Advances in Consumer Research, 20, 123-128.

Piacentini, M.G. and Banister, E.N. (2009). Managing anti-consumption in an excessive drinking culture. Journal of Business Research, 62(2), 279-288.

Richardson, B., and Turley, D. (2006). Support your local team: Resistance, subculture, and the desire for distinction. Advances in Consumer Research, 33, 175-180.

Richetin, J., Connor, M., and Perugini, M. (2011). Not doing is not the opposite of doing: Implications for attitudinal models of behavioural prediction. Personality and Social Psychology Bulletin, 37(1), 40-54.

Roche, A.M., Bywood, P.T., Boriagdan, J., Lunnay, B., Freeman, T., Lawton, L., Tovell, A., and Nicholas, R. (2007). Young people and alcohol: The role of cultural influences. National Centre for Education and Training on Addiction, Adelaide, Australia.

Shanker, A., Elliott, R., and Fitchett, J.A. (2009). Identity, consumption and narratives of socialization. Marketing Theory, 9(1), 75-79.

Stammerjohan, C., and Webster, C. (2002). Trait and situational antecedents to nonconsumption. Advances of Consumer Research, 29(1), 126-132.

Szmigin, I., Bengry-Howell, A., Griffin, C., Hackley, C., and Mistral, W. (2010). Social marketing, individual responsibility and the "culture of intoxication", European Journal of Marketing, 45(5), 759-779.

Thompson C.J., and Haytko, D.L. (1997). Speaking of fashion: Consumer's uses of fashion discourses and the appropriation of counterveiling cultural meanings. Journal of Consumer Research, 24(1), 15-24.

Thompson, C.J., Locander, W.B., and Pollio, H.R. (1989). Putting consumer experience back into consumer research: the philosophy and method of existential phenomenology. Journal of Consumer Research, 16(2), 133-147.

Thompson, C.J. (1997). Interpreting consumers: A hermeneutical framework for deriving marketing insights from texts of consumer's consumption stories. Journal of Marketing Research, 34(4), 438-456 
Thompson C. J. and Hirschman, E.C. (1995). Understanding the socialized body: A poststructuralist analysis of consumers' self-conception, body images, and self-care practices. Journal of Consumer Research, 22, 139-153

UK Department of Health. (2007). Safe, Sensible. Social. The next steps in the National Alcohol Strategy.

Valentine, G., Holloway, S.L., and Jayne, M. (2010). Contemporary cultures of abstinence and the night time economy: Muslim attitudes towards alcohol and the implications for social cohesion. Environment and Planning A, 42, 8-22.

Wooten, D.B. (2000). Qualitative steps toward an expanded model of anxiety in gift-giving. Journal of Consumer Research, 27(1), 84-95.

Zavestocki, S. (2002). Guest editorial: anti-consumption attitudes. Psychology and Marketing, 19(2), 121-6. 